\title{
Computerized tomographic volumetry for preoperative evaluation of split renal function in living donors
}

\author{
Ertugrul ${ }^{1 *}$, Karakaya $A^{2}$, Yanaral $\mathrm{T}^{3}$, Cakir $\mathrm{T}^{4}$, Unal $\mathrm{A}^{5}$ and Aydin $\mathrm{C}^{1}$ \\ ${ }^{1}$ Organ Transplantation Center, Medipol University, Faculty of Medicine, Istanbul, Turkey \\ ${ }^{2}$ Department of Radiology, Medipol University, Faculty of Medicine, Istanbul, Turkey \\ ${ }^{3}$ Department of Anesthesiology, Medipol University, Faculty of Medicine, Istanbul, Turkey \\ ${ }^{4}$ Department of Nuclear Medicine, Medipol University, Faculty of Medicine, Istanbul, Turkey \\ ${ }^{5}$ Department of Nephrology, Medipol University, Faculty of Medicine, Istanbul, Turkey
}

\begin{abstract}
Background: Kidney transplantation is the treatment of choice for end stage kidney disease, providing improved patient survival as compared to dialysis therapy. Generally nuclear renography is performed to estimate split kidney function (SRF), and computed tomography is done to evaluate vascular anatomy in preoperative investigation of living kidney donors. The aim of our study was to compare nuclear scintigraphy and CT based volumetry to evaluate SRF in living kidney donors in the selection of the kidney for donor nephrectomy.

Method: We designed a retrospective study to find out the relevance between the left and right kidney volumes calculated by CT and SRF measured by a nuclear renal scintigraphy. A total of 36 patients underwent live donor nephrectomy at Medipol University Hospital between April 2015 and April 2018.

Result: Mean age of the 36 donors was $42.7 \pm 13.4$ (23-67) years, and 20 (66.7\%) of them were female. Pearson correlation analysis test was done to determine the correlation of these techniques with percentage decrease of eGFR before donation and in postoperative $3^{\text {rd }}$ day. The p value was 0.714 and 0.06 for CT volumetry and nuclear scintigraphy when correlated with \% decrease in donor eGFR, respectively.
\end{abstract}

Conclusion: This current study suggests that CT volumetry gives similar results when compared to nuclear renography in calculating SRF of live kidney donors.

\section{Introduction}

Kidney transplantation is the treatment of choice for end stage kidney disease, providing improved patient survival as compared to dialysis therapy. On the other hand, because of organ shortage, living donors are used generally world-wide. In order to ensure donor safety and comfort, it requires a very careful preoperative evaluation process. Assessment of predonation kidney function and anatomy is an important factor to eliminate the risk of kidney disease in the living donor. Ideally, the nephron mass hypothesis suggests that the larger or more dominant kidney should remain with the donor [1]. There are no universal recommended guidelines about acceptable volume or function asymmetry when choosing right or left kidney for living donor nephrectomy. In many transplant centers, functional assessment of both kidneys is most commonly measured by nuclear scintigraphy although it has limitations such as radiation exposure, long procedure time, high cost and interpretation errors [2]. In addition, contrast-enhanced CT (or MRI) is used for vascular and anatomical evaluation and screening possible abnormalities [3].

Moreover, in the presence of a CT scan, assessment of split renal function (SRF) by nuclear scintigraphy has been questioned among transplant society recently [4]. In some current studies, it has been demonstrated that SRF could be measured by CT-deriven calculations of the kidney volume with different volumetry techniques [5-7]. The aim of our study was to compare nuclear scintigraphy and CT based volumetry to evaluate SRF in living kidney donors in the selection of the kidney for donor nephrectomy.

\section{Method}

We designed a retrospective study to find out the relevance between the left and right kidney volumes calculated by CT and SRF measured by a nuclear renal scintigraphy. Our study cohort consisted of 36 adult ( $>18$ years) donors. Electronic charts were retrospectively evaluated and donors of the pediatric patients, recipients who had an acute rejection or major complication alongside the donors with MRI angiography or whose CT scans performed elsewhere from our institution were excluded from the study. Donor serum Cr, 24-hour urine cretinine clearance $(\mathrm{CrCl})$ and estimated GFR (eGFR) calculated by Chronic Kidney Disease Epidemiology Collaboration (CKD-EPI) equation were investigated for the assessment of predonation kidney function [8]. Additionally, postdonation kidney function of the donor was calculated by eGFR test on postoperative day three. All of the donors had a contrast-enhanced CT during preparation process involving evaluation of the renal vascular anatomy, and a Tc-99mmercapto-acetyltriglycine (MAG3) (Tc99m-MAG3) scan to measure

${ }^{\star}$ Correspondence to: Ertugrul G, Organ Transplantation Center, Medipol University, Faculty of Medicine, TEM Avrupa Otoyolu Göztepe Çikişi, Bagcilar, Istanbul, Turkey, Tel: +90 212 4607777; Fax: +90 212 4706060; E-mail: mdgertugrul@gmail.com

Key words: living donor kidney transplantation, volumetry, split renal function.

Received: April 02, 2019; Accepted: April 11, 2019; Published: April 16, 2019 
preoperative SRF. Both volume and SRF calculation results was given as percentages.

\section{CT-Volumetry}

Renal length and volume were evaluated by CT executed by a 256-detector CT scanner (Philips 256-slice CT, Philips Electronics N.V). The multiphase CT study involved four abdominal scans got before ( 1 pre-contrast phase) and after ( 3 post-contrast phases with a slice thickness under $1.5 \mathrm{~mm}$ ) administration of contrast material (low osmolality, iodinated contrast at a dose of $2 \mathrm{~mL} / \mathrm{kg}$ body weight at a rate of $4 \mathrm{~mL} / \mathrm{s}$ ). Post-contrast phases were the cortico-medullary, tubulary and excretory phases. The renal delineation was made semiautomatically by mouse clicks on the renal cortex on a computer software (Philips Portal Medical Systems, Philips Healthcare Informatics, Inc.). The parts of collecting system, adipose tissue in the sinus, and cystic or solid masses were omitted. The total renal volume of each donor was calculated then. The total kidney volume for each donor was defined as the sum of the left $(\mathrm{L})$ and the right $(\mathrm{R})$ kidney volumes. The individual kidney contribution to overall kidney function was assumed proportional to its contribution to the total kidney volume based on the equation; \% measured kidney volume of interest= (individual $\mathrm{R}$ or $\mathrm{L}$ kidney volume) x 100 / (total $\mathrm{R}+\mathrm{L}$ kidney volume).

\section{Nuclear scintigraphy}

Nuclear imaging renograms were acquired using a parallel hole, low-energy, high-resolution collimator. Background activity was calculated from soft tissue regions of interest. Differential function was calculated from integrated background- and depth-corrected cortical activity.

\section{Analysis of donor renal function}

The percentage of decrease in estimated glomerular filtration rate of the donor was calculated with given formulae: $100 \mathrm{x}$ [postop third day eGFR - preop eGFR] / preop eGFR.

\section{Statistical analysis}

Statistical analysis was done with the SPSS Statistics software (version 20; IBM Corp., Armonk, NY). Qualitative data were given by percentage, quantitative data by mean \pm standard deviation. Pearson correlation analysis was used to compare two measurement methods and percentage of preoperative and postoperative eGFR difference. $\mathrm{P}$ values of 0.05 or less was considered statistically significant.

\section{Result}

A total of 36 patients underwent live donor nephrectomy at Medipol University Hospital between April 2015 and April 2018. After the elimination of unsuitable group of patients mentioned in the methods, a number of 36 donors were included in the study. Mean age of the 36 donors was $42.7 \pm 13.4$ (23-67) years, and 20 (66.7\%) of them were female. Table 1 shows the basic demographics of all the donors. Mean serum creatinine level and eGFR value before renal transplantation were $0.73 \pm 0.11 \mathrm{mg} / \mathrm{dL}$ and $106.9 \pm 15.7 \mathrm{l} / \mathrm{min} / 1.73$ $\mathrm{m}^{2}$, respectively. On postoperative third day, mean serum creatinine levels and calculated eGFR values of the donors were $1.04 \pm 0.17 \mathrm{mg} /$ $\mathrm{dL}$ and $77.4 \pm 15.5 \mathrm{ml} / \mathrm{min} / 1.73 \mathrm{~m}^{2}$, respectively.

Table 1 shows the comparison of demographic findings of the 36 donor patients.

We evaluated the status of correlation between proportional kidney volume calculated by CT volumetry and SRF by nuclear scintigraphy. We measured the difference noticed between right and left kidneys for each technique. Percentage contributions of the left and right kidney to the total renal function evaluated by the Tc99m DTPA were $51.13 \pm 3.66$ and $48.87 \pm 3.66$, respectively. CT volume percentages of the left and right kidney were $50.39 \pm 2.75$ and 49.61 \pm 2.75 , respectively. Pearson correlation analysis test was done to determine the correlation of these techniques with percentage decrease of eGFR before donation and in postoperative $3^{\text {rd }}$ day (Table 2). The $\mathrm{p}$ value was 0.714 and 0.06 for CT volumetry and nuclear scintigraphy when correlated with \% decrease in donor eGFR, respectively.

Table 2 shows correlation of two different techniques with the \% decrease in eGFR.

\section{Discussion}

In this current study it has been shown that there is no statistically difference between CT-based volumetric measurements and nuclear scintigraphy in determining SRF. Outcomes of our investigation verify that in living donor kidney transplantation, volume of the kidneys is an important employable parameter of renal function. Therefore, volumetric studies can be regarded as a mean to evaluate predonation SRF.

To properly define the related participation of each kidney to total kidney function is utterly important in predonation assessment of living donors in order to provide donor comfort and safety. If an inequality detected in kidney function, the better functioning kidney should be left in the donor. Predonation assessment of split kidney function is done widely by nuclear renographic techniques $[3,5,9,10,11]$. In this technique, a radioisotope is injected systemically, and kidney uptake is quantified over time. Even though its common utilization, nuclear scintigraphy has important disadvantages, such as length of procedure, exposure to radiation, and calculation mistakes. On the other hand, CT angiography that is routinely used in many transplant centers to assess renal vascular and parenchymal anatomy has its own benefits of minimizing radiation exposure, procedure time and operator dependency. Advanced devices which have the ability to produce rapid and dependent 3D images of the kidneys are widely accessible now [12]. Thus, use of CT- based techniques to measure SRF encouraged transplant physicians as a noninvasive, easy to perform single study, hence facilitating and accelerating donor assessment [2].

Table 1. Basic demographic characteristics $(n=36)$

\begin{tabular}{|l|c|}
\hline Donor Age (years) & $42.7 \pm 13.4$ \\
\hline $\begin{array}{l}\text { Donor Sex Ratio (Male/Female) } \\
(\mathrm{n} / \%)\end{array}$ & $16(33.3 \%) / 20(66.7 \%)$ \\
\hline Mean 24 Hours Creatinine Clearance (milliliter/minute) & $119 \pm 25.7$ \\
\hline Mean Donor Serum Creatinine (milligram/deciliter) & $0.73 \pm 0.11$ \\
\hline $\begin{array}{l}\text { Mean Preoperative } \\
\text { Estimated Glomerular Filtration Rate } \\
\text { (milliliter/minute/1.73 square meters) }\end{array}$ & $114.13 \pm 15.9$ \\
\hline $\begin{array}{l}\text { Mean postop 3rd day Estimated Glomerular Filtration } \\
\text { Rate (milliliter /minute/1.73 square meters) }\end{array}$ & $67.4 \pm 16$ \\
\hline
\end{tabular}

Table 2. Correlation of two different techniques with the $\%$ decrease in eGFR

\begin{tabular}{|c|c|}
\hline $\begin{array}{c}\text { Difference in Contribution with the } \\
\text { Preferred Kidney }\end{array}$ & $\begin{array}{c}\text { \% Decrease in Estimated Glomerular } \\
\text { Filtration Rate }\end{array}$ \\
\hline $\begin{array}{c}\text { CT volumetry } \\
\text { Pearson correlation (r) / Sig. (2-tailed) (p) }\end{array}$ & $0.07 / 0.714$ \\
\hline $\begin{array}{c}\text { Scintigraphy } \\
\text { Pearson correlation (r) / Sig. (2-tailed) (p) }\end{array}$ & $0.336 / 0.069$ \\
\hline
\end{tabular}


While the mean glomerular volume is closely correlated with kidney weight, volumetric studies has been suggested to be used as a substitute [9]. Therefore, kidney volume, has also been indicated as a significant factor for nephron number [13]. To evaluate SRF with $\mathrm{CT}$, kidney volume is measured and compared between left and right kidneys, accepting that volume is correlated with function in healthy donors without parenchymal abnormalities. There are variable techniques used for CT volumetric studies $[2,4,5,9]$. In this study, the definition of kidneys was made semi-automatically by mouse clicks on the renal cortex using software on a computer. Then the individual kidney contribution to overall kidney function was assumed by an equation as defined in methods section.

The evaluation of kidney function in living donors is highly crucial to avoid renal failure during their remaining lifetime. In a previous study, it is indicated that after donor nephrectomy, $12 \%$ of donors develop chronic kidney disease defined as an eGFR $<60 \mathrm{ml} /$ $\mathrm{min} / 1.73 \mathrm{~m} 2$ [14]. Consequently, assessment of donor SRF before donor nephrectomy is extremely critical to decide to the side of nephrectomy. In our institution, we both investigate the 24 hours creatinine clearance and eGFR before donation process. In addition, we checked the postdonation kidney function with postoperative $3^{\text {rd }}$ day eGFR test. Then we analyzed the correlation of SRF calculations of CT volumetry and nuclear scintigrahy with the percentage of decrease in renal function measured as predonation and postdonation difference of the eGFR, and we found no statistically difference between two techniques.

Our study has some limitations: First of all, this is a single center study with a relatively small number of populations. Secondly kidney function is measured by eGFR which may have restrictions related to formula used for calculation.

\section{Conclusion}

This current study suggests that CT volumetry gives similar results when compared to nuclear renography in calculating SRF of live kidney donors. Consequently, when the present technical limitations of renal scintigraphy such as radiation exposure, long procedure time, high cost and interpretation errors are considered, a CT only protocol may be more useful for predonation preparation of the donors in the context of estimating split renal function.

\section{References}

1. Courbebaisse M, Gaillard F, Tissier AM, Fournier C, Le Nestour A, et al. (2016) Association of mGFR of the Remaining Kidney Divided by Its Volume before Donation with Functional Gain in mGFR among Living Kidney Donors. Clin J Am Soc Nephrol 11: 1369-1376. [Crossref]

2. Barbas AS, Li Y, Zair M, Van JA, Famure O, et al. (2016) CT volumetry is superior to nuclear renography for prediction of residual kidney function in living donors. Clin Transplant 30: 1028-1035. [Crossref]

3. Abramowicz D, Cochat P, Claas F, Dudley C, Harden P, et al. (2013) Guideline. The European Renal Best Practice (ERBP) Transplantation guideline development group. Nephrol Dial Transpl 28: ii1-ii71.

4. Halleck F, Diederichs G, Koehlitz T, Slowinski T, Engelken F, et al. (2013) Volume matters: CT-based renal cortex volume measurement in the evaluation of living kidney donors. Transpl Int 26: 1208-1216. [Crossref]

5. Yanishi M, Kinoshita H, Yoshida T, Takayasu K, Yoshida K, et al. (2015) Comparison of Renal Scintigraphy and Computed Tomographic Renal Volumetry for Determining Split Renal Function and Estimating Post-Transplant Renal Function. Transplant Proc 47: 2700-2702. [Crossref]

6. Mitsui Y, Sadahira T, Araki M, Wada K, Tanimoto R, et al. (2018) The assessment of renal cortex and parenchymal volume using automated CT volumetry for predicting renal function after donor nephrectomy. Clin Exp Nephrol 22: 453-458. [Crossref]

7. Gardan E, Jacquemont L, Perret C, Heudes PM, Gourraud PA, et al. (2018) Renal cortical volume: High correlation with pre- and post-operative renal function in living kidney donors. Eur J Radiol 99: 118-123. [Crossref]

8. Levey AS, Stevens LA, Schmid CH, Zhang YL, Castro AF, et al. (2009) A New Equation to Estimate Glomerular Filtration Rate. Ann Intern Med 150: 604. [Crossref]

9. Diez A, Powelson J, Sundaram CP, Taber TE, Mujtaba MA, et al. (2014) Correlation between CT-based measured renal volumes and nuclear-renography-based split renal function in living kidney donors. Clinical diagnostic utility and practice patterns. Clin Transplant 28: 675-682. [Crossref]

10. Patankar K, Low RS, Blakeway D, Ferrari P (2014) Comparison of computer tomographic volumetry versus nuclear split renal function to determine residual renal function after living kidney donation. Acta Radiol 55: 753-760. [Crossref]

11. Lentine KL, Kasiske BL, Levey AS, Adams PL, Alberú J, et al. (2017) KDIGO Clinical Practice Guideline on the Evaluation and Care of Living Kidney Donors. Transplantation 101: S7-S105. [Crossref]

12. Rastogi N, Sahani DV, Blake MA, Ko DC, Mueller PR (2006) Evaluation of living renal donors: accuracy of three-dimensional 16-section CT. Radiology 240: 136-144. [Crossref]

13. Kobayashi K, Censullo ML, Rossman LL, Kyriakides PN, Kahan BD, et al. (2007) Interventional Radiologic Management of Renal Transplant Dysfunction: Indications, Limitations, and Technical Considerations. Radiographics 27: 1109-1130. [Crossref]

14. Garg AX, Muirhead N, Knoll G, Yang RC, Prasad GV, et al. (2006) Proteinuria and reduced kidney function in living kidney donors: A systematic review, meta-analysis, and meta-regression. Kidney Int 70: 1801-1810. [Crossref]

Copyright: (C2019 Ertugrul G. This is an open-access article distributed under the terms of the Creative Commons Attribution License, which permits unrestricted use, distribution, and reproduction in any medium, provided the original author and source are credited. 